\title{
Randomised controlled trial to improve health and reduce substance use in established psychosis (IMPaCT): cost- effectiveness of integrated psychosocial health promotion
}

Margaret Heslin ${ }^{1 \dagger}$ (D, Anita Patel ${ }^{2^{*}+}$, Daniel Stahl ${ }^{3}$, Poonam Gardner-Sood ${ }^{3}$, Manyara Mushore ${ }^{4}$, Shubulade Smith ${ }^{3}$, Kathryn Greenwood ${ }^{5,6}$, Oluwadamilola Onagbesan ${ }^{3}$, Conan O'Brien ${ }^{3}$, Catherine Fung ${ }^{3}$, Ruth Ohlsen ${ }^{7}$, David Hopkins ${ }^{8,9}$, Philippa Lowe ${ }^{10}$, Maurice Arbuthnot ${ }^{11}$, Stan Mutatsa ${ }^{12}$, Gill Todd ${ }^{13}$, Anna Kolliakou ${ }^{3}$, John Lally ${ }^{3}$, Brendon Stubbs ${ }^{14}$, Khalida Ismail ${ }^{3}$, Anthony David ${ }^{3}$, Robin Murray ${ }^{3}$, Zerrin Atakan ${ }^{3}$ and Fiona Gaughran ${ }^{3}$

\footnotetext{
Abstract

Background: There is mounting evidence that people with severe mental illness have unhealthy lifestyles, high rates of cardiovascular and metabolic diseases, and greater risk of early mortality. This study aimed to assess the cost-effectiveness of a health promotion intervention seeking to improve physical health and reduce substance use in people with psychosis.

Methods: Participants with a psychotic disorder, aged 18-65 years old and registered on an enhanced care approach programme or equivalent were recruited from community mental health teams in six mental health trusts in England. Participants were randomisation to either standard community mental health team care (treatment as usual) or treatment as usual with an integrated health promotion intervention (IMPaCT). Cost-effectiveness and cost-utility analyses from health and social care and societal perspectives were conducted alongside a cluster randomised controlled trial. Total health and social care costs and total societal costs at 12 and 15 months were calculated as well as cost-effectiveness (incremental costeffectiveness ratios and cost-effectiveness acceptability curves) at 15 months based on quality of life (SF-36 mental and physical health components, primary outcome measures) and quality adjusted life years (QALYs) using two measures, EQ-5D-3 L and SF-36. Data were analysed using bootstrapped regressions with covariates for relevant baseline variables.

(Continued on next page)
}

\footnotetext{
* Correspondence: anitapatelconsulting@gmail.com

${ }^{\dagger}$ Equal contributors

${ }^{2}$ Centre for Primary Care and Public Health, Blizard Institute, Barts and The

London School of Medicine and Dentistry, Queen Mary University of London,

Yvonne Carter Building, 58 Turner Street, London E1 2AB, UK

Full list of author information is available at the end of the article
} 
(Continued from previous page)

Results: At 12-15 months 301 participants had full data needed to be included in the economic evaluation. There were no differences in adjusted health and social care costs ( $£ 95,95 \% \mathrm{Cl}-£ 1410$ to $£ 1599$ ) or societal costs $(£ 675,95 \% \mathrm{Cl}-£ 1039$ to $£ 2388)$ between the intervention and control arms. Similarly, there were no differences between the groups in the SF-36 mental component $(-0.80,95 \% \mathrm{Cl}-3.66$ to 2.06), SF-36 physical component $(-0.68,95 \% \mathrm{Cl}-3.01$ to 1.65$)$, QALYs estimated from the SF-36 (-0.00, -0.01 to 0.00$)$ or QALYs estimated from the EQ-5D-3 L $(0.00,95 \% \mathrm{Cl}-0.01$ to 0.02$)$.

Cost-effectiveness acceptability curves for all four outcomes and from both cost perspectives indicate that the probability of the health promotion intervention being cost-effective does not exceed 0.4 for willingness to pay thresholds ranging from $£ 0-£ 50,000$.

Conclusions: Alongside no evidence of additional quality of life/clinical benefit, there is also no evidence of cost-effectiveness.

Trial registration: ISRCTN58667926. Date retrospectively registered: 23/04/2010. Recruitment start date: 01/03/2010.

Keywords: Health promotion, Psychosis, Quality of life, Economic, Cost

\section{Background}

There is mounting evidence that people with severe mental illness have unhealthy lifestyles [1-4], high rates of cardiovascular and metabolic diseases [5], and greater risk of early mortality [6, 7]. These major health implications inevitably carry substantial economic consequences, both within and outside of the health system [8]. There is an urgent need to address modifiable lifestyle factors to reduce cardiovascular and other diseases associated with morbidity and mortality [2, 4, 9, 10]. There is a particularly urgent need locally, with the levels of cardiometabolic abnormalities in South London [11] among the highest reported in the world [5]. One promising way to achieve this is through increasing staff awareness of their role in achieving this [12].

We developed a new health promotion intervention (HPI) designed to be integrated into routine clinical care and implemented by the patient's usual care coordinator - the main clinical contact (from one of a number of professional backgrounds) for patients with psychosis receiving secondary mental health services in the UK. We present here the findings from an economic evaluation of this intervention within a cluster randomised controlled trial. To our knowledge there are no other economic evaluations of integrated health promotion interventions for people with psychosis. Economic evaluations of specific, separate interventions $[13,14]$ suggest greater costs associated with achieving outcome improvements, rather than any clear economic advantages. Thus there remains a need for cost-effective approaches to addressing this issue.

\section{Methods}

\section{Design and intervention}

Full details of the pragmatic multi-centre phase III twoarm cluster RCT trial and findings from its effectiveness study have been described elsewhere [15-17]. Briefly, community care coordinators with a minimum of four patients on their caseload in participating community mental health teams (CMHTs) were approached in a random sequence and invited to participate. After gaining their informed consent to participate, we approached patients on their caseload meeting the inclusion criteria (18-65 years old with a diagnosis of psychotic disorder (ICD-10 F20-29, F31.2, F32.3, F33.3) under the care of a Community Mental Health Team (CMHT) registered on an enhanced level of the Care Approach Programme (CPA) or equivalent). Exclusion criteria are described elsewhere [15] and we did not recruit from first episode services.

After completing baseline assessments on all consenting patients in a care co-ordinator's caseload, care coordinators were randomised, stratified by borough, using randomisation blocks of random sizes to deliver either treatment as usual (TAU) with an integrated 9 month intensive HPI (IMPaCT therapy) or treatment as usual alone. All care coordinators were provided a one-off information session on mental and physical health issues. All outcome assessments were undertaken by researchers blind to treatment allocation. It was hypothesised that the intervention arm would have better quality of life and health outcomes at 12 month follow-up, and that this would be sustained 3 months after completion of the formal intervention, at 15 -months follow up.

The economic evaluation was integrated into the trial and was based on primary data collection within the trial. It focused on costs at 15 months (for the previous 3 months) from two perspectives: health and social care; and societal.

Ethical approval was obtained from the joint South London and Maudsley and the Institute of Psychiatry NHS Ethics Committed (REC Ref no 09/HO80/41). 


\section{Data collection}

An adapted version of the Client Service Receipt Inventory (CSRI) [18] was used to measure individual-level resource use. It covered the use of (all-cause) secondary and community-based health and social care services, prescription medication, time off work, and key social security benefits received by participants and carers. It was administered as a retrospective self-report questionnaire-based interview conducted by assessors blind to treatment allocation. It covered the previous 6month period at baseline and 12 month follow-up, and the previous 3-month period at 15 month follow-up. Data related to delivery of the intervention were recorded by care coordinators using specifically designed proformas.

\section{Unit costs}

Unit costs (see online supplementary material) were applied to individual-level resource use data to calculate total costs. Briefly, unit costs for most hospital and primary care services were obtained from the NHS Reference Costs [19] (inflated to 2011-12 prices using the Hospital and Community Health Services Pay and Prices Index or Retail price index as appropriate [20]) and the Unit Costs of Health and Social Care [20]. Medication unit costs, taken from the British National Formulary [21] were converted into cost per milligram $(\mathrm{mg})$ based on the most cost-efficient pack size, choosing maintenance doses over initial treatment doses and generic formulations over branded ones to obtain conservative estimates. Lost productivity costs were estimated by applying national average wage rates to lost work days (human capital approach) and were capped at 5 days per week.

The cost of the intervention is described in full elsewhere [17]. Briefly, the intervention consisted of four components and we estimated costs for each of these: production of manuals (excluding the development work); training care coordinators; ongoing supervision of care coordinators; and implementation of the intervention by care coordinators to trial participants. The mean cost of the IMPaCT intervention was $£ 226.40$. The comparable cost for patients in the TAU arm was $£ 3.52$ in relation to the one-off information session provided to all care coordinators.

All costs are reported in pounds sterling $(£)$ at 2011-12 prices. Costs related to the intervention were not discounted since they were incurred within the first year. However, all other costs (and outcomes) related to the 1215 month assessment period were discounted using a rate of $3.5 \%$ [22].

\section{Outcomes}

All outcome measures were administered as intervieweradministered self-report questionnaires at baseline, 12 and 15 month follow-ups. Cost-effectiveness analyses were based on the joint primary outcome measures, the SF-36 mental component score and SF-36 physical component score [23]. Cost-utility analyses were based on QALYs derived from the SF-36 (US version 1) via the SF-6D and the EQ-5D-3 L [24]. Appropriate utility weights were attached to health states for each measure at baseline, 12 and 15 months [25, 26]. QALY gains between 12 months and 15 months were then calculated using the total area under the curve approach with linear interpolation between assessment points [27].

\section{Analyses}

Data were analysed using Stata (version 11) [28]. Participants were analysed according to the group to which they were randomised regardless of intervention compliance. No normalisation was used, and outliers were not adjusted or removed.

Costs and outcomes were compared at baseline, 12 and 15 months and are presented as mean values by arm with standard deviations. Mean differences and 95\% confidence intervals (CIs) were obtained by nonparametric bootstrap regressions (ordinary least squares (OLS), 1000 repetitions) to account for the non-normal distribution commonly found in economic data, with adjustment for clustering at the care coordinator level. To provide more relevant treatment-effect estimates [29] (OLS) regressions to calculate mean differences in costs at 12 and 15 months included covariates for the baseline value for the same cost category, baseline SF-36 mental component score, baseline SF-36 physical component score, baseline SF-36 utility and baseline EQ-5D-3 L utility, plus baseline demographic variables expected to be associated with costs (gender, ethnicity, borough). Similarly, comparisons of outcome data included covariates for baseline: SF-36 mental component score, SF-36 physical component score, SF-36 utility and EQ-5D-3 L utility, plus baseline demographic variables expected to be associated with outcome (gender, age, ethnicity, place of birth and borough).

Individual item non-response for the CSRI was minimal given the interview approach taken. Where it occurred, an item cost was imputed using the mean cost for the same item for other users in the same trial arm and at the same assessment point. Where this was not possible, the overall cost component was imputed using the mean cost for the same cost component in the same trial arm at the same assessment point. For medication data, a series of assumptions and imputations were necessary depending on the nature of the missing information, as follows, making use of available data components where possible. If medication name was missing, we applied an average prescription cost (from Department of Health prescription cost analysis (PCA)), accounting for the reported number of days on that 
medication, and assuming the prescription lasted for 1 month. If number of days on medication was missing, a PCA average item cost for that medication was used, with the assumption that the patient was prescribed that medication just once in that period. If dose was missing, a PCA average item cost was used, assuming each prescription lasted 1 month but accounting for number of days on the medication. If the dose unit was missing, a PCA average item cost was used assuming each prescription lasted 1 month, with an account of the number of days on medication. If dose frequency was missing, a PCA average item cost was used, assuming each prescription lasted 1 month, again accounting for number of days. Finally, if it was unknown whether the medication was administered as a depot, a PCA average item cost was used assuming each prescription lasted 1 month, accounting for the number of days on medication.

The base case analysis was undertaken using cases with available relevant cost and/or outcome data (i.e. excluding those lost to follow-up for the CSRI, EQ-5D$3 \mathrm{~L}$ or SF-36 assessments as relevant).

The economic evaluation takes a decision-making approach which ignores statistical significance (of both the clinical and economic outcomes) and instead focusses on the probability of one intervention being cost-effective compared to another in light of the available data. This is the approach recommended over traditional reliance on decision rules regarding statistical significance [30, 31]. Cost-effectiveness and cost-utility analyses were conducted at 15 months to focus on the more pertinent question of whether any effect lasted beyond the end of the intervention, but 12 month cost and outcome data are also reported for information. The economic evaluation examined 8 possible cost-outcome combinations (accounting for the two cost perspectives and four outcomes). Incremental cost-effectiveness ratios (ICERs) were calculated for any combination showing both higher costs and better outcomes in either the intervention group or control group (it is unnecessary to calculate ICERs for any combinations where one group shows both lower costs and better outcomes as it is then considered to 'dominate' the other group).

Uncertainty around cost-effectiveness/cost-utility was explored using cost-effectiveness planes and costeffectiveness acceptability curves (CEACs) based on the net-benefit approach [32]. These curves are an alternative to confidence intervals around ICERs and show the probability that one intervention is cost-effective compared to the other, for a range of values that a decision maker would be willing to pay for an additional unit of an outcome. Net benefits for each participant were calculated using the following formula, where $\lambda$ is the willingness to pay for one additional unit of outcome: Net benefit $=(\lambda \times$ outcome $)-$ cost.
A series of net benefits were calculated for each individual for a $\lambda$ range that would include any policy-making perspectives relevant at the time of analysis. After calculating net benefits for each participant for each value of $\lambda$, coefficients of differences in net benefits between the trial arms were obtained through a series of bootstrapped linear regressions (1000 repetitions) of group upon net benefit which included the same covariates used for the comparisons of mean costs and outcomes (i.e. baseline value of: the same cost category, SF-36 mental component score; SF-36 physical component score; EQ-5D-3 L utility score; SF-36 utility score; gender; age; ethnicity; place of birth; borough) and an adjustment for clustering by care coordinator. The resulting coefficients were then examined to calculate for each value of $\lambda$ the proportion of times that the intervention group had a greater net benefit than the control group. These proportions were then plotted to generate CEACs for all eight cost-outcome combinations.

Although the intervention was conducted for 9 months, cost-effective analyses were conducted on the 12-15 month data. This was done for two reasons. Firstly, to allow a broad enough time window to conduct outcome assessments, which was necessary due to the data collection approach needed here. Secondly, a 9month assessment could misrepresent cost-effectiveness of the intervention if any outcome improvements or cost savings were subsequently not sustained even for 3 months.

\section{Sensitivity analyses}

We conducted four sensitivity analyses to check the robustness of the base case analyses defined above. First, we explored the potential impact of excluding those lost to follow-up. We examined key socio-demographic and clinical characteristics for those included and excluded from the analyses and conducted an intention to treat (ITT) analysis which included those lost to follow-up by imputing missing total costs and outcomes using imputation in STATA [28]. Imputations of costs and outcomes were based on variables which were expected to be associated with costs and outcomes. For cost imputations, these variables were baseline and 12 month values for the: equivalent cost category; SF-36 mental component score; SF-36 physical component score; EQ-5D-3 L utility score; SF-36 utility score; plus gender, ethnicity, borough, age, place of birth and care coordinator. Imputation of outcomes was based on baseline and 12 month values of the: SF-36 mental component score; SF-36 physical component score; EQ-5D-3 L utility score; SF-36 utility score; plus gender, age, ethnicity, age, place of birth and borough, and care coordinator. Secondly, to explore the potential impact of having follow-up interviews conducted outside of the planned 
assessment window (more than 30 days before or after the follow-up date), we conducted a 'correct time window' analysis including only those trial participants whose data were collected within the correct window. Thirdly, to explore the potential impact of insufficient implementation of the IMPaCT Therapy, we conducted a per protocol analysis which included only those intervention arm participants who received the pre-defined minimum of six intervention sessions of at least $30 \mathrm{~min}$ duration each. Finally, to explore the potential impact of care coordinator drop out, we conducted analyses which included only those participants whose care coordinator remained the same throughout the study.

For each of these sensitivity analyses, we examined whether conclusions concerning the mean difference in costs or outcomes between the two trial arms differed to those drawn from the base case analyses.

\section{Patient and public involvement}

Service users and carers, with lived experience were involved throughout the study, from applying to funding to managing the steering group, to co-authoring this paper. Focus groups were also run with service users to refine our approach. Additionally a delphi process with service users was used to develop the health promotion intervention.

\section{Results}

One hundred four care coordinators were recruited and randomized. Four hundred six patients from randomized care coordinators were eligible and consented for the trial. Fifty two care coordinators with 213 patients were randomized to the IMPaCT Therapy and 52 care coordinators with 193 patients were randomized to TAU.

Responses rates for the client service receipt inventory were $100 \%(\mathrm{n} 405), 79 \%(\mathrm{n} 319)$ and $74 \%(\mathrm{n} 301)$ at baseline, 12 months and 15 months respectively and similar between the intervention and control group. Corresponding response rates for the SF-36 were 99\% (n402), $77 \%$ (n313) and 73\% (n297), and for the EQ-5D-3 L were 100\% (n404), 78\% (n315) and 74\% (n301). All participants had full data on intervention use. There were no notable differences in the baseline characteristics of the sub-samples included in the base case analyses of those with available data against the full sample.

\section{Resource use}

Resource use patterns at 12 and 15 months are described in Tables 1 and 2. These were not compared statistically since the economic evaluation was focused on costs and cost-effectiveness/utility, and to avoid problems associated with multiple testing. The data suggest that both arms were broadly balanced in their use of core services both before and during the study. As would be expected for this group of patients, service use is very broad in both nature and sector, illustrating the complexity of their care provision.

\section{Costs and outcomes}

We present total costs from the two cost perspectives and sub-totals for the components within these (generally by sector) (Table 3 ). There were no differences in these sub-totals by trial arm, except that the cost of the intervention was naturally higher in the intervention group given the additional inputs required compared with the control group (adjusted mean difference $£ 311$, 95\% CI $£ 267$ to $£ 355$ ) and costs borne by charities were higher in the intervention group at 12 months (adjusted mean difference $£ 80,95 \% \mathrm{CI} £ 9$ to $£ 151$ ). Health and social care and lost productivity formed the largest components of total societal costs.

Comparisons of total costs from both health and social care and societal perspectives at 15 months suggested no difference between the trial arms although the 95\% confidence intervals suggest a tendency for societal costs to be greater in the intervention arm (Table 3). All sensitivity analyses confirmed this conclusion.

There were no differences in outcome at any of the assessments (Table 4). As with cost data, all sensitivity analyses confirmed this conclusion.

\section{Cost-effectiveness}

From a health and social care perspective, the probability of the IMPaCT Therapy being cost-effective does not exceed 0.4 for any of the examined willingness to pay thresholds for QALY gains (based on either the SF-36 or EQ-5D-3 L) or for the physical and mental component scores gains (Fig. 1). Similarly, the probability of costeffectiveness from a societal perspective does not exceed 0.2 (Fig. 1).

\section{Discussion}

We found no evidence of a clear difference in health and social care or societal costs between the two trial arms, in quality of life outcomes or cost-effectiveness as a result of delivering a comprehensive and integrated health promotion intervention to people with established psychosis. The corresponding outcome evaluation discusses the many possible explanations for lack of outcome effect and the same factors will likely have impacted on costs and cost-effectiveness since a significant factor was lack of successful implementation of the IMPaCT Therapy. Briefly, they include policy and practice steps towards greater parity between mental and physical health care which took place during the study may have improved the health of both groups, staff turn-over meant a sizable proportion of participants did not receive the intervention, and care co-ordinators 
Table 1 Resource use at 12 month follow-up (for the previous 6 months)

\begin{tabular}{|c|c|c|c|c|c|c|c|}
\hline \multirow[b]{2}{*}{ Resource } & \multirow[b]{2}{*}{ Unit } & \multicolumn{3}{|c|}{ Intervention $(n=160)$} & \multicolumn{3}{|c|}{ Controls $(n=159)$} \\
\hline & & Number of users & Mean contacts $^{a}$ & $\overline{S D}$ & Number of users & Mean contacts $^{a}$ & $\overline{S D}$ \\
\hline \multicolumn{8}{|l|}{ Specialist accommodation } \\
\hline Supported housing / assisted living & bed day & 37 & 182 & 1 & 30 & 179 & 12 \\
\hline Sheltered housing & bed day & 1 & 182 & - & 6 & 158 & 60 \\
\hline Hostel / shelter & bed day & 4 & 182 & 0 & 5 & 152 & 68 \\
\hline \multicolumn{8}{|l|}{ Hospital inpatient } \\
\hline Inpatient & bed day & 42 & 182 & 1 & 41 & 173 & 34 \\
\hline \multicolumn{8}{|l|}{ Hospital outpatient } \\
\hline Psychiatric outpatient & visit & 13 & 4 & 2 & 6 & 2 & 1 \\
\hline Non-psychiatric / general / medical outpatient & visit & 14 & 3 & 2 & 16 & 2 & 2 \\
\hline Diabetes clinic & visit & 11 & 3 & 3 & 9 & 1 & 1 \\
\hline Blood tests & visit & 79 & 5 & 4 & 69 & 4 & 3 \\
\hline Psychiatric day hospital & visit & 2 & 2 & 1 & 1 & 6 & - \\
\hline Non-psychiatric / general / medical day hospital & visit & 2 & 1 & 0 & 2 & 4 & 4 \\
\hline Day surgery centre & visit & 4 & 2 & 1 & 6 & 1 & 0 \\
\hline A\&E department & visit & 22 & 2 & 4 & 19 & 2 & 1 \\
\hline X-ray & visit & 23 & 1 & 1 & 14 & 1 & $<1$ \\
\hline Substance misuse clinic & visit & 3 & 10 & 12 & 3 & 7 & 4 \\
\hline Dietetics & visit & 4 & 2 & 3 & 1 & 1 & - \\
\hline \multicolumn{8}{|l|}{ Community based day services } \\
\hline Community based services & visit & 70 & 44 & 40 & 63 & 40 & 36 \\
\hline \multicolumn{8}{|l|}{ Community based professionals } \\
\hline Care coordinator & surgery visit & 95 & 9 & 7 & 98 & 7 & 7 \\
\hline Care coordinator & home visit & 67 & 9 & 8 & 64 & 8 & 8 \\
\hline Care coordinator & phone call & 32 & 8 & 10 & 29 & 6 & 7 \\
\hline Home treatment team & surgery visit & 1 & 1 & - & 1 & 1 & - \\
\hline Home treatment team & home visit & 10 & 17 & 11 & 3 & 13 & 7 \\
\hline Home treatment team & phone call & 1 & 2 & - & 0 & - & - \\
\hline Crisis resolution team & surgery visit & 1 & 3 & - & 0 & - & - \\
\hline Crisis resolution team & home visit & 1 & 2 & - & 0 & - & - \\
\hline Crisis resolution team & phone call & 1 & 2 & - & 0 & - & - \\
\hline Community psychiatric nurse & surgery visit & 1 & 6 & - & 2 & 4 & 4 \\
\hline Community psychiatric nurse & home visit & 2 & 5 & 2 & 3 & 3 & 3 \\
\hline Social worker & surgery visit & 4 & 3 & 3 & 5 & 2 & 1 \\
\hline Social worker & home visit & 2 & 9 & 4 & 2 & 3 & 2 \\
\hline Psychiatrist & surgery visit & 85 & 2 & 2 & 86 & 2 & 4 \\
\hline Psychiatrist & home visit & 7 & 5 & 9 & 8 & 6 & 8 \\
\hline Psychologist & surgery visit & 10 & 11 & 10 & 15 & 11 & 13 \\
\hline Psychologist & home visit & 1 & 14 & - & 1 & 24 & - \\
\hline Psychologist & phone call & 0 & - & - & 1 & 1 & - \\
\hline Psychotherapist & surgery visit & 1 & 4 & - & 1 & 3 & - \\
\hline Counsellor & surgery visit & 9 & 4 & 5 & 5 & 4 & 2 \\
\hline GP & surgery visit & 110 & 3 & 3 & 104 & 3 & 4 \\
\hline GP & home visit & 1 & 3 & - & 2 & 3 & 2 \\
\hline
\end{tabular}


Table 1 Resource use at 12 month follow-up (for the previous 6 months) (Continued)

\begin{tabular}{|c|c|c|c|c|c|c|c|}
\hline \multirow[b]{2}{*}{ Resource } & \multirow[b]{2}{*}{ Unit } & \multicolumn{3}{|c|}{ Intervention $(n=160)$} & \multicolumn{3}{|l|}{ Controls $(n=159)$} \\
\hline & & Number of users & Mean contacts $^{a}$ & $\overline{S D}$ & Number of users & Mean contacts ${ }^{a}$ & $\overline{S D}$ \\
\hline GP & phone call & 1 & 1 & - & 1 & 1 & - \\
\hline Blood test at GP & surgery visit & 38 & 2 & 1 & 44 & 2 & 2 \\
\hline Diabetes nurse & surgery visit & 9 & 2 & 4 & 6 & 2 & 1 \\
\hline Diabetes nurse & phone call & 0 & - & - & 3 & 1 & 0 \\
\hline Practice nurse & surgery visit & 33 & 3 & 3 & 21 & 11 & 39 \\
\hline Practice nurse & home visit & 0 & - & - & 1 & 6 & - \\
\hline Practice nurse & phone call & 1 & 2 & - & 0 & - & - \\
\hline District nurse & surgery visit & 2 & 6 & 6 & 0 & - & - \\
\hline Occupational therapist & surgery visit & 4 & 6 & 7 & 2 & 6 & 4 \\
\hline Occupational therapist & home visit & 4 & 22 & 34 & 2 & 3 & 0 \\
\hline Occupational therapist & phone call & 1 & 2 & - & 1 & 2 & - \\
\hline Dietician & surgery visit & 3 & 1 & 0 & 6 & 3 & 3 \\
\hline Home help & home visit & 11 & 53 & 52 & 7 & 61 & 59 \\
\hline Meals on wheels & home visit & 2 & 13 & 16 & 0 & - & - \\
\hline Pharmacist for advice & surgery visit & 16 & 2 & 2 & 14 & 3 & 2 \\
\hline Pharmacist for advice & phone call & 2 & 1 & 0 & 0 & - & - \\
\hline NHS direct & phone call & 0 & - & - & 2 & 2 & 1 \\
\hline Samaritans & phone call & 5 & 79 & 90 & 4 & 24 & 45 \\
\hline Medication & & 159 & - & - & 158 & - & - \\
\hline
\end{tabular}

${ }^{\mathrm{a}}$ Mean for users only

All quantities are rounded to nearest whole number

implementing the intervention struggled to deliver the minimum dose.

\section{Strengths and limitations of the study}

This study was a pragmatic trial based in five NHS mental health trusts. The intervention was specifically designed to be accessible to as many people as possible by being delivered by care coordinators as part as care as usual rather than requiring people to attend add-on or group appointments. However, there were also some methodological limitations. Data on resource use were collected by self-report. This makes it subject to participant recall bias. However, the approach was necessary in relation to strengths of the study design - our interest in the full range of formal services used by this group, given the mental and physical health focus here, and also in broader societal costs which are of particular relevance for a patient group whose health and care needs can have economic impacts upon multiple sectors of society. Even a narrower cost perspective would have been hindered by a lack of integration of relevant health and social care sector client records and a possible lack of comparability in record systems for all study sites. There is though evidence for the reliability of the selfreport approach in similar populations $[33,34]$ and there is no reason to believe that any biases related to data collection would be imbalanced between the two trial arms, particularly since the CSRI was administered by blinded assessors.

A further limitation is we may have double-counted resource use associated with the IMPaCT Therapy. We collected this information separately from care coordinators, rather than from patient participants, to avoid unblinding the assessors conducting the participant interviews. Patients would anyway have found it difficult to separately report care related to the IMPaCT Therapy since it was designed to be integrated into usual care. However, this inevitably means that patient reports of contacts with their care coordinator include inputs associated with the intervention. While this may doublecount absolute estimates of costs for the intervention arm, this would result in over-estimation and thus bias against, rather than for, the intervention arm.

There has been some discussion around the validity of the SF-36 and EQ-5D-3 L among study participants with mental health problems, especially those with schizophrenia and other psychoses [35]. Although the two measures are commonly used, and indeed recommended, for economic evaluation to inform policymaking in England, Brazier et al. [35] suggest that neither scale performs particularly well in these particular patient groups in terms of quantitative testing against 
Table 2 Resource use at 15 month follow-up (for the previous 3 months)

\begin{tabular}{|c|c|c|c|c|c|c|c|}
\hline \multirow[b]{2}{*}{ Resource } & \multirow[b]{2}{*}{ Unit } & \multicolumn{3}{|c|}{ Intervention $(n=152)$} & \multicolumn{3}{|l|}{ Controls $(n=149)$} \\
\hline & & Number of users & Mean contacts $^{a}$ & $\overline{S D}$ & Number of users & Mean contacts $^{a}$ & $\overline{S D}$ \\
\hline \multicolumn{8}{|l|}{ Specialist accommodation } \\
\hline Supported housing / assisted living & bed day & 36 & 90 & 3 & 30 & 90 & 3 \\
\hline Sheltered housing & bed day & 2 & 70 & 30 & 6 & 91 & 0 \\
\hline Hostel / shelter & bed day & 1 & 81 & - & 5 & 91 & 0 \\
\hline \multicolumn{8}{|l|}{ Hospital inpatient } \\
\hline Inpatient & bed day & 39 & 90 & 8 & 41 & 90 & 2 \\
\hline \multicolumn{8}{|l|}{ Hospital outpatient } \\
\hline Psychiatric outpatient & visit & 8 & 2 & 1 & 1 & 1 & - \\
\hline Non-psychiatric / general / medical outpatient & visit & 7 & 1 & $<1$ & 10 & 2 & 2 \\
\hline Diabetes clinic & visit & 4 & 1 & 0 & 6 & 1 & 0 \\
\hline Blood tests & visit & 63 & 2 & 2 & 56 & 3 & 1 \\
\hline Psychiatric day hospital & visit & 2 & 5 & 1 & 0 & - & - \\
\hline Non-psychiatric / general / medical day hospital & visit & 1 & 2 & - & 3 & 1 & 0 \\
\hline Day surgery centre & visit & 3 & 1 & 0 & 2 & 1 & 0 \\
\hline A\&E department & visit & 15 & 1 & 1 & 15 & 1 & 1 \\
\hline X-ray & visit & 10 & 1 & 0 & 12 & 1 & 1 \\
\hline Substance misuse clinic & visit & 2 & 24 & 17 & 1 & 1 & - \\
\hline Dietetics & visit & 2 & 1 & 0 & 2 & 1 & 0 \\
\hline \multicolumn{8}{|l|}{ Community based day services } \\
\hline Community based services & visit & 57 & 20 & 19 & 50 & 26 & 25 \\
\hline \multicolumn{8}{|l|}{ Community based professionals } \\
\hline Care coordinator & surgery visit & 78 & 5 & 6 & 70 & 4 & 4 \\
\hline Care coordinator & home visit & 59 & 5 & 3 & 52 & 4 & 3 \\
\hline Care coordinator & phone call & 28 & 5 & 6 & 26 & 5 & 5 \\
\hline Home treatment team & surgery visit & 2 & 2 & 1 & 1 & 8 & - \\
\hline Home treatment team & home visit & 7 & 9 & 8 & 4 & 12 & 13 \\
\hline Crisis resolution team & surgery visit & 1 & 1 & - & 0 & - & - \\
\hline Crisis resolution team & home visit & 1 & 1 & - & 1 & 1 & - \\
\hline Early intervention team & surgery visit & 1 & 36 & - & 0 & - & - \\
\hline Community psychiatric nurse & surgery visit & 6 & 6 & 4 & 13 & 4 & 2 \\
\hline Community psychiatric nurse & home visit & 2 & 4 & 1 & 3 & 1 & 1 \\
\hline Community psychiatric nurse & phone call & 3 & 8 & 10 & 4 & 5 & 5 \\
\hline Social worker & surgery visit & 2 & 8 & 6 & 4 & 5 & 5 \\
\hline Social worker & home visit & 0 & - & - & 2 & 7 & 7 \\
\hline Social worker & phone call & 0 & - & - & 1 & 5 & - \\
\hline Psychiatrist & surgery visit & 65 & 1 & 1 & 60 & 1 & 1 \\
\hline Psychiatrist & home visit & 3 & 5 & 6 & 5 & 4 & 5 \\
\hline Psychologist & surgery visit & 14 & 6 & 5 & 8 & 5 & 5 \\
\hline Psychologist & home visit & 1 & 10 & - & 0 & - & - \\
\hline Psychotherapist & surgery visit & 2 & 10 & 3 & 0 & - & - \\
\hline Psychotherapist & home visit & 0 & - & - & 1 & 1 & - \\
\hline Counsellor & surgery visit & 3 & 2 & 2 & 1 & 2 & - \\
\hline
\end{tabular}


Table 2 Resource use at 15 month follow-up (for the previous 3 months) (Continued)

\begin{tabular}{|c|c|c|c|c|c|c|c|}
\hline \multirow[b]{2}{*}{ Resource } & \multirow[b]{2}{*}{ Unit } & \multicolumn{3}{|c|}{ Intervention $(n=152)$} & \multicolumn{3}{|l|}{ Controls $(n=149)$} \\
\hline & & Number of users & Mean contacts $^{a}$ & $\overline{S D}$ & Number of users & Mean contacts ${ }^{a}$ & $\overline{S D}$ \\
\hline GP & surgery visit & 81 & 3 & 2 & 83 & 2 & 1 \\
\hline GP & home visit & 1 & 1 & - & 0 & - & - \\
\hline GP & phone call & 1 & 2 & - & 1 & 4 & - \\
\hline Blood test at GP & surgery visit & 26 & 2 & 5 & 27 & 1 & 1 \\
\hline Diabetes nurse & surgery visit & 4 & 2 & 2 & 3 & 1 & 1 \\
\hline Diabetes nurse & home visit & 1 & 1 & - & 0 & - & - \\
\hline Practice nurse & surgery visit & 16 & 2 & 2 & 21 & 2 & 1 \\
\hline Practice nurse & phone call & 1 & 1 & - & 0 & - & - \\
\hline District nurse & surgery visit & 3 & 21 & 34 & 2 & 46 & 62 \\
\hline District nurse & home visit & 1 & 24 & - & 0 & - & - \\
\hline Occupational therapist & surgery visit & 4 & 12 & 9 & 5 & 5 & 4 \\
\hline Occupational therapist & home visit & 2 & 13 & 16 & 3 & 12 & 0 \\
\hline Occupational therapist & phone call & 1 & 3 & - & 0 & - & - \\
\hline Dietician & surgery visit & 1 & 1 & - & 6 & 2 & 1 \\
\hline Dietician & home visit & 0 & - & - & 1 & 12 & - \\
\hline Home help & home visit & 12 & 38 & 52 & 4 & 39 & 37 \\
\hline Meals on wheels & home visit & 4 & 47 & 33 & 1 & 15 & - \\
\hline Pharmacist for advice & surgery visit & 6 & 3 & 2 & 8 & 3 & 4 \\
\hline Pharmacist for advice & phone call & 2 & 2 & 1 & 1 & 1 & - \\
\hline NHS direct & phone call & 2 & 7 & 8 & 5 & 3 & 5 \\
\hline Samaritans & phone call & 4 & 36 & 39 & 4 & 15 & 21 \\
\hline Medication & & 149 & & & 145 & & \\
\hline
\end{tabular}

${ }^{a}$ Mean for users only

All quantities are rounded to nearest whole number

psychometric criteria and that both have a limited coverage of domains identified as relevant by people with mental health problems. Thus, it is unclear whether the lack of QALY difference between the two trial arms reflects a lack of intervention effect or limitations associated with the measurement properties of these two health-related quality of life measures. However, given the lack of effect based on the SF-36 mental and physical component scores, and all other outcome measures, it is unlikely that there was a difference in QALYs that we have been unable to detect.

Although the intervention was conducted for 9 months, cost-effective analyses were conducted on the 12-15 month data. There could have been larger cost and outcome differences at 9 months (the end of intervention) which reduced over time thus no significant differences were seen at 12 and 15 months. However, this ensures the costeffectiveness of the intervention could not be misrepresented if any outcome improvements or cost savings were subsequently not sustained even for 3 months.

Finally, the time horizon of the evaluation is likely to have been insufficient to identify all relevant outcomes for this patient group, particularly given the longer term nature of the impacts of physical health problems. However, it is unlikely that any effects of the intervention would transpire in the longer term if absent in the short term.

We used the human capital approach to valuing productivity loss rather than the friction cost method. While the human capital approach may over-estimate absolute values for lost productivity, such over-estimation will only impact the findings of the economic evaluation if productivity outcomes are different between the control and intervention groups, which does not appear to be the case here. Further, results from a societal perspective, which includes productivity losses, is consistent with results from a health and social care perspective.

\section{Comparison with previous research}

While a number of studies have demonstrated effectiveness of interventions to address lifestyle factors in similar patient groups [35-38] few include an economic evaluation.

Verhaeghe et al. [13] investigated the costeffectiveness of a health promotion targeting physical 
Table 3 Costs at baseline, 12 and 15 months (2011/12 prices, all 15 month costs, except the intervention costs, are discounted)

\begin{tabular}{|c|c|c|c|c|c|c|c|c|c|c|}
\hline & \multirow[b]{2}{*}{$\begin{array}{l}\text { valid } \\
n\end{array}$} & \multicolumn{2}{|c|}{$\begin{array}{l}\text { Intervention } \\
n=213\end{array}$} & \multirow[b]{2}{*}{$\begin{array}{l}\text { valid } \\
n\end{array}$} & \multicolumn{2}{|c|}{$\begin{array}{l}\text { Control } \\
n=193\end{array}$} & \multirow[t]{2}{*}{$\begin{array}{l}\text { Unadjusted } \\
\text { mean difference }\end{array}$} & \multirow[t]{2}{*}{$95 \% \mathrm{Cl}^{\mathrm{d}}$} & \multirow[t]{2}{*}{$\begin{array}{l}\text { Adjusted mean } \\
\text { difference }^{\mathrm{e}}\end{array}$} & \multirow[t]{2}{*}{$95 \% \mathrm{Cl}^{\mathrm{e}}$} \\
\hline & & $\begin{array}{l}\text { Mean } \\
E\end{array}$ & SD & & $\begin{array}{l}\text { Mean } \\
E\end{array}$ & $S D$ & & & & \\
\hline \multicolumn{11}{|l|}{ Component Costs at Baseline } \\
\hline $\begin{array}{l}\text { Health \& social care excluding } \\
\text { intervention }^{\mathrm{b}}\end{array}$ & 212 & 10,242 & 13,374 & 193 & 9714 & 13,767 & 528 & -2953 to 4010 & 967 & -2442 to 4435 \\
\hline Charity $^{\mathrm{b}}$ & 212 & 83 & 611 & 193 & 80 & 435 & 3 & -109 to 115 & -22 & -137 to 94 \\
\hline Lost productivity ${ }^{b}$ & 212 & 8755 & 5964 & 193 & 7472 & 6311 & 1283 & -354 to 2920 & 456 & -894 to 1806 \\
\hline Patient $^{\mathrm{b}}$ & 212 & 72 & 433 & 193 & 188 & 188 & 35 & -31 to 102 & 33 & -37 to 104 \\
\hline Benefits $^{\mathrm{b}}$ & 212 & 2211 & 1006 & 193 & 2009 & 940 & $202^{\mathrm{a}}$ & 13 to $391^{\mathrm{a}}$ & 127 & -70 to 324 \\
\hline \multicolumn{11}{|l|}{ Component Costs at 12 month } \\
\hline $\begin{array}{l}\text { Health \& social care excluding } \\
\text { intervention }\end{array}$ & 160 & 10,220 & 12,341 & 159 & 10,196 & 16,987 & 24 & -4219 to 4267 & -1596 & -5145 to 1954 \\
\hline Charity $^{\mathrm{b}}$ & 160 & 120 & 369 & 159 & 61 & 256 & 60 & -6 to 125 & $80^{\mathrm{a}}$ & 9 to $151^{a}$ \\
\hline Lost productivity ${ }^{\mathrm{b}}$ & 160 & 8882 & 5998 & 159 & 7707 & 6333 & 1174 & -317 to 2665 & 1038 & -367 to 2443 \\
\hline Patient ${ }^{b}$ & 160 & 84 & 369 & 159 & 53 & 300 & 31 & -38 to 100 & 25 & -46 to 96 \\
\hline Benefit $^{\mathrm{b}}$ & 160 & 2328 & 931 & 159 & 2129 & 957 & 200 & -14 to 413 & 87 & -105 to 279 \\
\hline \multicolumn{11}{|l|}{ Component Costs at 15 month } \\
\hline $\begin{array}{l}\text { Health \& social care excluding } \\
\text { interventionc }\end{array}$ & 152 & 4874 & 6317 & 149 & 4708 & 6383 & 166 & -1577 to 1910 & -231 & -1734 to 1272 \\
\hline Charity $^{\mathrm{c}}$ & 152 & 63 & 215 & 149 & 49 & 230 & 14 & -39 to 67 & 24 & -37 to 84 \\
\hline Lost productivity ${ }^{c}$ & 152 & 4731 & 2674 & 149 & 3880 & 3027 & $850^{\mathrm{a}}$ & 127 to $1573^{\mathrm{a}}$ & 608 & -25 to 1240 \\
\hline Patient ${ }^{c}$ & 152 & 24 & 141 & 149 & 30 & 162 & -6 & -38 to 27 & -6 & -37 to 25 \\
\hline Benefits $^{c}$ & 152 & 1089 & 439 & 149 & 1049 & 441 & 40 & -70 to 150 & -24 & -125 to 76 \\
\hline Intervention & 213 & 316 & 173 & 193 & 4 & 0 & $312^{\mathrm{a}}$ & 267 to $357^{\mathrm{a}}$ & $3142^{a}$ & 268 to $359^{a}$ \\
\hline \multicolumn{11}{|l|}{ Total Costs at 15 months } \\
\hline $\begin{array}{l}\text { Health \& social care including } \\
\text { intervention }^{f}\end{array}$ & 152 & 5209 & 6326 & 149 & 4711 & 6383 & 498 & -1248 to 2244 & 95 & -1410 to 1599 \\
\hline $\begin{array}{l}\text { Societal perspective including } \\
\text { intervention }^{f}\end{array}$ & 152 & 11,116 & 7271 & 149 & 9720 & 7707 & 1396 & -684 to 3476 & 675 & -1039 to 2388 \\
\hline
\end{tabular}

All figures are rounded to nearest whole number

${ }^{a}$ Confidence interval excludes zero

${ }^{\mathrm{b}}$ Costs for a 6 month retrospective period

${ }^{c}$ Costs for a 3 month retrospective period

${ }^{\mathrm{d}}$ Adjusting for clustering of care coordinator only

encludes covariates for baseline: equivalent cost, SF-36 mental component score, SF-36 physical component score, EQ-5D-3 L utility, SF-36 utility, gender, ethnicity and borough, plus clustering for care coordinator

${ }^{\mathrm{f}}$ Fifteen month costs discounted

activity and healthy eating in people with mental illness using a Markov decision model. The intervention consisted of 10 weeks of psycho-educational and behavioural group-based sessions, group based exercise (weekly 30 min supervised walking sessions), and individual support from the mental health nurses. The authors reported an incremental cost-effectiveness ratio of Euro 27,096 per QALY in men and Euro 40,139 per QALY in women although this was very sensitive to modelling assumptions.

Meenan et al. [14] reported on a randomised controlled trial and economic evaluation of a lifestyle intervention designed to reduce weight among individuals with serious mental illnesses who were taking antipsychotic medications. The authors reported no significant change in EQ-5D scores but reported ICERs between $\$ 1623$ to $\$ 2527$ per kilogram reduced depending on which costs were included and which cohort of patients were included (completers versus intention to treat). The authors also reported ICERs from $\$ 467$ to $\$ 727$ per $\mathrm{mg} / \mathrm{dL}$ reduced (fasting glucose) depending on which costs and cohort were used.

Both these studies thus suggest greater costs associated with intervening to produce improved outcomes in this population. 
Table 4 Outcomes at baseline, 12 and 15 months (all 15 month outcomes discounted)

\begin{tabular}{|c|c|c|c|c|c|c|c|c|c|c|}
\hline & \multicolumn{3}{|c|}{$\begin{array}{l}\text { Intervention } \\
\mathrm{n}=213\end{array}$} & \multicolumn{3}{|l|}{$\begin{array}{l}\text { Control } \\
n=193\end{array}$} & \multirow[t]{2}{*}{$\begin{array}{l}\text { Unadjusted mean } \\
\text { difference }^{b}\end{array}$} & \multirow[t]{2}{*}{$95 \% \mathrm{Cl}^{\mathrm{b}}$} & \multirow[t]{2}{*}{$\begin{array}{l}\text { Adjusted mean } \\
\text { difference }^{c}\end{array}$} & \multirow[t]{2}{*}{$95 \% \mathrm{Cl}^{\mathrm{C}}$} \\
\hline & valid $n$ & Mean & $S D$ & valid $n$ & Mean & $S D$ & & & & \\
\hline \multicolumn{11}{|l|}{ Baseline } \\
\hline SF-36 mental component score & 213 & 41.37 & 13.26 & 193 & 42.25 & 11.81 & -0.88 & -3.44 to 1.68 & -0.26 & -1.55 to 1.02 \\
\hline SF-36 physical component score & 213 & 45.83 & 10.94 & 193 & 47.04 & 9.26 & -1.20 & -3.31 to 0.91 & -0.60 & -1.72 to 0.52 \\
\hline SF-36 utility & 210 & 0.69 & 0.16 & 192 & 0.71 & 0.14 & -0.02 & -0.05 to 0.02 & 0.00 & -0.01 to 0.01 \\
\hline EQ-5D-3 L utility & 211 & 0.76 & 0.31 & 193 & 0.79 & 0.28 & -0.02 & -0.08 to 0.04 & 0.01 & -0.04 to 0.06 \\
\hline \multicolumn{11}{|l|}{12 months } \\
\hline SF-36 mental component score & 160 & 43.18 & 13.31 & 158 & 44.09 & 13.47 & -0.91 & -3.94 to 2.11 & -0.05 & -2.64 to 2.55 \\
\hline SF-36 physical component score & 160 & 46.76 & 11.23 & 158 & 49.02 & 10.55 & -2.27 & -4.74 to 0.21 & -1.45 & -3.56 to 0.66 \\
\hline SF-36 utility & 158 & 0.70 & 0.16 & 155 & 0.71 & 0.15 & -0.02 & -0.05 to 0.02 & -0.00 & -0.03 to 0.02 \\
\hline EQ-5D-3 L utility & 159 & 0.80 & 0.25 & 156 & 0.80 & 0.28 & 0.00 & -0.06 to 0.06 & 0.03 & -0.03 to 0.08 \\
\hline \multicolumn{11}{|l|}{15 months } \\
\hline SF-36 mental component score & 152 & 42.47 & 13.58 & 149 & 45.01 & 13.65 & -2.54 & -6.00 to 0.92 & -0.80 & -3.66 to 2.06 \\
\hline SF-36 physical component score & 152 & 47.25 & 11.62 & 149 & 48.54 & 9.88 & -1.29 & -4.02 to 1.44 & -0.68 & -3.01 to 1.65 \\
\hline SF-36 utility & 149 & 0.66 & 0.14 & 148 & 0.70 & 0.15 & $-0.03^{\mathrm{a}}$ & -0.07 to $-0.00^{\mathrm{a}}$ & -0.02 & -0.05 to 0.01 \\
\hline SF-36 based QALY gain & 134 & 0.17 & 0.03 & 139 & 0.17 & 0.09 & -0.01 & -0.01 to 0.00 & -0.00 & -0.01 to 0.00 \\
\hline EQ-5D-3 L utility & 152 & 0.77 & 0.24 & 149 & 0.80 & 0.25 & -0.02 & -0.09 to 0.04 & 0.00 & -0.06 to 0.06 \\
\hline EQ-5D-3 L based QALY gain & 137 & 0.19 & 0.05 & 140 & 0.20 & 0.06 & -0.00 & -0.02 to 0.01 & 0.00 & -0.01 to 0.02 \\
\hline
\end{tabular}

${ }^{a}$ Confidence interval excludes zero

${ }^{\mathrm{b}}$ Adjusting for clustering of care coordinator

Includes covariates for baseline: SF-36 mental component score, SF-36 physical component score, EQ-5D-3 L utility, SF-36 utility, gender, age, ethnicity, place of birth and borough, plus clustering for care coordinator

\section{Implications for policy}

As reported by Gaughran et al. [16] a health promotion intervention targeting multiple risk factors has proved difficult to integrate into usual care for many contextual and pragmatic reasons. This leaves an unaddressed care gap that carries significant implications for both patient health and economic costs. An RCT of a similar intervention from Denmark, likewise failed to show a clinically significant effect [39]. Other studies show promise that interventions targeting specific issues $[36,38,40]$ may be simpler to implement or more effective in improving physical outcomes. It would be vital to assess the resource and cost-effectiveness implications of such models since add-on services would present additional care costs in the short-term. Current financial pressures in the NHS mental health care suggest challenges in delivering new services whether through new funding or reallocation of existing budgets - hence our attempt to develop an intervention that can be provided pragmatically within existing patient contacts.
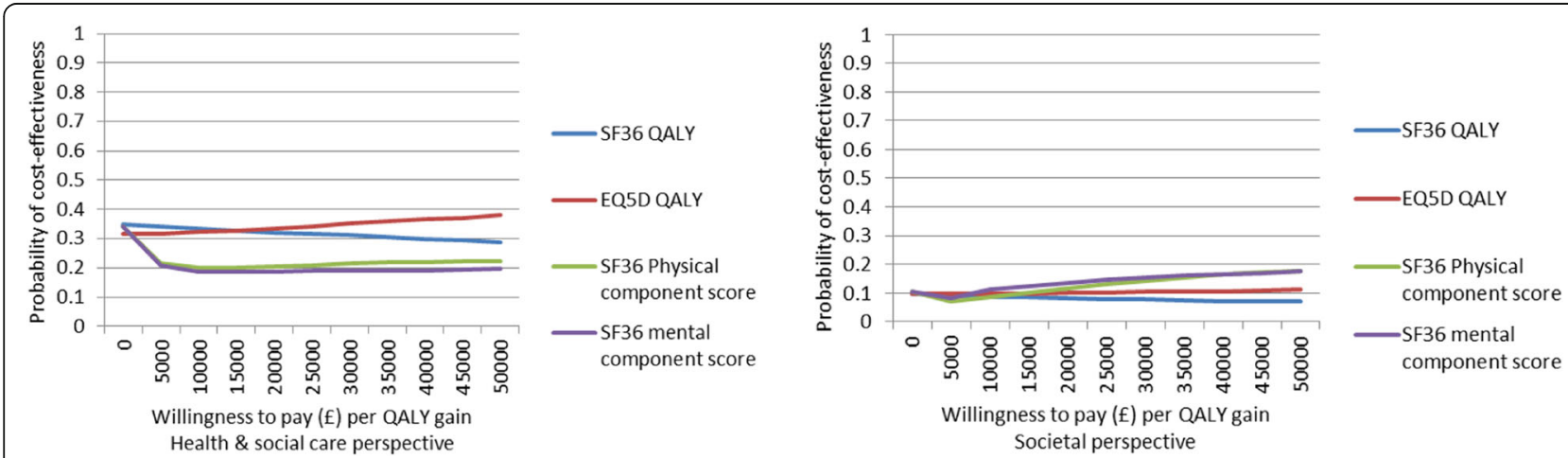

Fig. 1 Cost-effectiveness acceptability curves for SF-36 physical and mental component scores plus SF-36 and EQ-5D-3 L based QALYS from a health \& social care perspective and societal perspective 


\section{Conclusions}

We found no evidence that an integrated health promotion intervention for people with established psychosis improves outcomes or achieves savings in health and social care or societal costs. Given the long term economic implications of increased cardiovascular risk and premature mortality for this population, it is vital that other options for early intervention are developed and assessed for cost-effectiveness is given the multiple pressures on health and social care budgets now and in the foreseeable future.

\begin{abstract}
Abbreviations
CEAC: cost effectiveness acceptability curve; CEP: cost effectiveness plane; CMHT: community mental health teams; CPA: Care Approach Programme; CSRI: Client Service Receipt Inventory; HPI: health promotion intervention; ICER: incremental cost effectiveness ratio; IMPaCT: integrated health promotion intervention; PCA: prescription cost analysis; QALYs: quality adjusted life years; RCT: randomised controlled trial; TAU: treatment as usual

\section{Acknowledgements}

Not applicable.

\section{Funding}

This paper summarises independent research funded by the National Institute for Health Research (NIHR) under its IMPACT Programme (Grant Reference Number RP-PG- 0606-1049). FG receives funding from the NIHR Collaboration for Leadership in Applied Health Research \& Care Funding scheme. The views expressed in this publication are those of the author(s) and not necessarily those of the NHS, the National Institute for Health Research or the Department of Health.
\end{abstract}

\section{Availability of data and materials}

The datasets generated and/or analysed during the current study are not publicly available due to them containing information that could compromise research participant privacy/consent but suitably anonymised sub-sections can be made available from the corresponding author on reasonable request.

\section{Authors' contributions}

$A P, D S, S S, K G, D H, G T, K I, A D, R M, Z A$ and FG conceived and designed the study. MH conducted all data analysis with oversight from AP. PGS, MM, OO, $\mathrm{COB}, \mathrm{CF}, \mathrm{RO}, \mathrm{PL}, \mathrm{MA}, \mathrm{SM}, \mathrm{AK}, \mathrm{J}$ and $\mathrm{BS}$ all made substantial contributions to acquisition. MH, AP, DS, SS, KG, DH, GT, Kl, AD, RM, ZA, FG PGS, MM, OO, $\mathrm{COB}, \mathrm{CF}, \mathrm{RO}, \mathrm{PL}, \mathrm{MA}, \mathrm{SM}, \mathrm{AK}, \mathrm{JL}$ and $\mathrm{BS}$ all made substantial contributions to interpretation of data. MH and AP drafted the original manuscript. All authors were involved in critically revising the manuscript for important intellectual content, gave final approval of the published version and are accountable for all aspects of the work

\section{Ethics approval and consent to participate}

Full informed written consent was obtained before entry into the study. Ethical approval was obtained from the joint South London and Maudsley and the Institute of Psychiatry NHS Ethics Committed (REC Ref no 09/HO80/41).

\section{Consent for publication}

Not applicable.

\section{Competing interests}

FG has received honoraria for advisory work and lectures from Roche, BMS, Lundbeck, Otsaka and Sunovion, is a collaborator on a NHS Innovations project co-funded by Janssen and has a family member with professional links to Lilly and GSK, including share options. RM has received speaker honoraria from Janssen, Astra-Zeneca, Lilly, BMS and Roche. KG and KI have received speaker fees for Eli Lilly, Janssen, Sanofi. Other authors have nothing to disclose.

\section{Publisher's Note}

Springer Nature remains neutral with regard to jurisdictional claims in published maps and institutional affiliations.

\section{Author details}

${ }^{1}$ King's Health Economics, Institute of Psychiatry, Psychology \& Neuroscience at King's College London, London, UK. ${ }^{2}$ Centre for Primary Care and Public Health, Blizard Institute, Barts and The London School of Medicine and Dentistry, Queen Mary University of London, Yvonne Carter Building, 58 Turner Street, London E1 2AB, UK. ${ }^{3}$ Institute of Psychiatry, Psychology \& Neuroscience at King's College London, London, UK. ${ }^{4}$ London South Bank University, London, UK. ${ }^{5}$ R\&D department, Sussex Partnership NHS Foundation Trust, Brighton, UK. 'School of Psychology, University of Sussex, Brighton, UK. 'Florence Nightingale Faculty of Nursing and Midwifery, King's College London, London, UK. ${ }^{8}$ Division of Ambulatory Care and Local Networks, King's College Hospital NHS Foundation Trust, London, UK. ' King's College London School of Medicine, London, UK. ${ }^{10}$ Carer Advisor, London, UK. ${ }^{11}$ Service User Advisor, London, UK. ${ }^{12}$ City University, London, UK.

${ }^{13}$ South London and Maudsley NHS Foundation Trust, London, UK.

${ }^{14}$ Physiotherapy Department, South London and Maudsley NHS Foundation Trust, London, UK

Received: 16 March 2017 Accepted: 5 December 2017

Published online: 22 December 2017

\section{References}

1. Brown S, Birtwistle J, Roe L, Thompson C. The unhealthy lifestyle of people with schizophrenia. Psychol Med. 1999;29(3):697-701.

2. McCreadie RG. Diet, smoking and cardiovascular risk in people with schizophrenia: descriptive study. Br J Psychiatry. 2003;183(6):534-9.

3. Dipasquale S, Pariante CM, Dazzan P, Aguglia E, McGuire P, Mondelli V. The dietary pattern of patients with schizophrenia: a systematic review. J Psychiatr Res. 2013:47(2):197-207.

4. Stubbs B, Williams J, Gaughran F, Craig T. How sedentary are people with psychosis? A systematic review and meta-analysis. Schizophr Res. 2016; 171(1):103-9.

5. Vancampfort D, Stubbs B, Mitchell AJ, De Hert M, Wampers M, Ward PB, Rosenbaum S, Correll CU. Risk of metabolic syndrome and its components in people with schizophrenia and related psychotic disorders, bipolar disorder and major depressive disorder: a systematic review and metaanalysis. World Psychiatry. 2015;14(3):339-47.

6. Brown S, Inskip H. \& Barraclough. Causes of the excess mortality of schizophrenia. Br J Psychiatry. 2000;177:212-7.

7. Walker ER, McGee RE, Druss BG. Mortality in mental disorders and global disease burden implications: a systematic review and meta-analysis. JAMA Psychiatry. 2015;72(4):334-41.

8. The Schizophrenia Commission. The abandoned illness: a report from the schizophrenia commission. London: Rethink Mental Illness; 2012.

9. Robson D, Gray R. Serious mental illness and physical health problems: a discussion paper. Int J Nurs Stud. 2007:44(3):457-66.

10. Hert M, Correll CU, Bobes J, Cetkovich-Bakmas MA, Cohen DA, Asai I, Detraux J, Gautam S, Möller HJ, Ndetei DM, Newcomer JW. Physical illness in patients with severe mental disorders. I. Prevalence, impact of medications and disparities in health care. World Psychiatry. 2011;10(1): 52-77.

11. Gardner-Sood P, Lally J, Smith S, Atakan Z, Ismail K, Greenwood KE, Keen A, O'Brien C, Onagbesan O, Fung C, Papanastasiou E. Cardiovascular risk factors and metabolic syndrome in people with established psychotic illnesses: baseline data from the IMPaCT randomized controlled trial. Psychol Med. 2015;45(12):2619-29.

12. Phelan M, Stradins L, Morrison S. Physical health of people with severe mental illness: can be improved if primary care and mental health professionals pay attention to it. BMJ. 2001;322(7284):443-4.

13. Verhaeghe N, De Smedt D, De Maeseneer J, Maes L, Van Heeringen C, Annemans L. Cost-effectiveness of health promotion targeting physical activity and healthy eating in mental health care. BMC Public Health. 2014; 14(1):1.

14. Meenan RT, Stumbo SP, Yarborough MT, Leo MC, Yarborough BJH, Green CA. An economic evaluation of a weight loss intervention program for people with serious mental illnesses taking antipsychotic medications. Adm Policy Ment Health Ment Health Serv Res. 2016:1-12. 
15. Gaughran F, Stahl D, Ismail K, Atakan Z, Lally J, Gardner-Sood P, Patel A, David A, Hopkins D, Harries B, Lowe P. Improving physical health and reducing substance use in psychosis-randomised control trial (IMPACT RCT): study protocol for a cluster randomised controlled trial. BMC Psychiatry. 2013;13(1):263.

16. Gaughran F, Stahl D, Ismail K, Greenwood K, Atakan Z, Gardner-Sood P, Stubbs B, Hopkins D, Patel A, Lally J, Lowe P, Arbuthnot M, Orr D, Eberhard J, David AS, Murray RM, Smith S. Randomised control trial of the effectiveness of an integrated psychosocial health promotion intervention aimed at improving health and reducing substance use in established psychosis (IMPaCT). BMC Psychiatry (in press).

17. Gaughran F, Stahl D, Ismail K, Greenwood K, Atakan Z, Gardner-Sood P, Stubbs B, Hopkins D, Patel A, Lally J, Lowe P, Arbuthnot M, Orr D, Eberhard J, David AS, Murray RM, Smith S. The IMPACT Programme. HTA. BMC Psychiatry (in press).

18. Beecham J \& Knapp M. Costing psychiatric interventions. In: Thornicroft G (ed). Measuring mental health needs (2nd edition). 2001. Gaskell, London.

19. Department of Health. NHS reference costs 2010/11. URL: http://www.dh. gov.uk/en/Publicationsandstatistics/Publications/ PublicationsPolicyAndGuidance/DH_131140

20. Curtis L. PSSRU: unit costs of Health \& Social Care 2012, 2012. Kent: Personal Social Services Research Unit.

21. Joint Formulary Committee (March 2012). British national formulary. 63rd ed. London: BMJ Group and Pharmaceutical Press; 2012.

22. Treasury HM. The green book: appraisal and evaluation in central government. London: TSO; 2003.

23. Ware J, Sherbourn C. The MOS, 36 item short-form health survey (SF-36). I: conceptual framework and item selection. Med Care. 1992;30:473-83.

24. EuroQol Group. EuroQol: a facility for the measurement of health-related quality of life. Health Policy. 1990;16:199-208.

25. Brazier J, Roberts J, Deverill M. The estimation of a preference-based measure of health from the SF-36. J Health Econ. 2002;21(2):271-92.

26. Dolan P, Gudex C, Kind P, Williams A. A social tariff for EuroQol: results from a UK population survey. York: University of York; 1995.

27. Manca A, Hawkins N, Sculpher MJ. Estimating mean QALYs in trial-based cost-effectiveness analysis: the importance of controlling for baseline utility. Health Econ. 2003;14:487-96.

28. StataCorp. Stata' 11.2 for Windows. 2011. College Station, TX, StataCorp LP.

29. Assmann SF, Pocock SJ, Enos LE, Kasten LE. Subgroup analysis and other (mis) uses of baseline data in clinical trials. Lancet. 2000;355(9209):1064-9.

30. Claxton K. The irrelevance of inference: a decision-making approach to the stochastic evaluation of health care technologies. J Health Econ. 1999;18(3):341-64.

31. Claxton $\mathrm{K}$, Sculpher M, Drummond M. A rational framework for decision making by the National Institute for clinical excellence (NICE). Lancet. 2002; 360(9334):711-5.

32. Briggs $\mathrm{AH}$. A Bayesian approach to stochastic cost-effectiveness analysis. Health Econ. 1999;8:257-61.

33. Calsyn RJ, Allen G, Morse GA, Smith R, Tempelhoff B. Can you trust selfreport data provided by homeless mentally ill individuals? Eval Rev. 1993;17:353-66

34. Goldberg RW, Seybolt DC, Lehman A. Reliable self-report of health service use by individuals with serious mental illness. Psychiatr Serv. 2002;53:879-81.

35. Brazier J, Connell J, Papaioannou D, Mukuria C, Mulhern B, Peasgood T, et al. A systematic review, psychometric analysis and qualitative assessment of generic preference-based measures of health in mental health populations and the estimation of mapping functions from widely used specific measures. Health Technol Assess. 2014;18(34).

36. Caemmerer J, Correll CU, Maayan L. Acute and maintenance effects of nonpharmacologic interventions for antipsychotic associated weight gain and metabolic abnormalities: a meta-analytic comparison of randomized controlled trials. Schizophr Res. 2012;140:159-68.

37. Brown S, Chan K. A randomized controlled trial of a brief health promotion intervention in a population with serious mental illness. J Ment Health. 2006;15(5):543-9.

38. Bartels SJ, Pratt SI, Aschbrenner KA, Barre LK, Jue K, Wolfe RS, Xie H, McHugo G, Santos M, Williams GE, Naslund JA. Clinically significant improved fitness and weight loss among overweight persons with serious mental illness. Psychiatric Services. 2013;64(8):729-36.
39. Speyer H, Christian Brix Nørgaard H, Birk M, Karlsen M, Storch Jakobsen A, Pedersen K, Hjorthøj C, Pisinger C, Gluud C, Mors O, Krogh J. The CHANGE trial: no superiority of lifestyle coaching plus care coordination plus treatment as usual compared to treatment as usual alone in reducing risk of cardiovascular disease in adults with schizophrenia spectrum disorders and abdominal obesity. World Psychiatry. 2016;15(2):155-65.

40. Daumit GL, Dickerson FB, Wang NY, Dalcin A, Jerome GJ, Anderson CA, Young DR, Frick KD, Yu A, Gennusa JV III, Oefinger M. A behavioral weightloss intervention in persons with serious mental illness. N Engl J Med. 2013; 368(17):1594-602.

\section{Submit your next manuscript to BioMed Central and we will help you at every step:}

- We accept pre-submission inquiries

- Our selector tool helps you to find the most relevant journal

- We provide round the clock customer support

- Convenient online submission

- Thorough peer review

- Inclusion in PubMed and all major indexing services

- Maximum visibility for your research

Submit your manuscript at www.biomedcentral.com/submit
) Biomed Central 